\title{
Structural Design of Asphalt Pavements: Principles and Practices in Various Design Guidelines
}

\author{
Animesh Das ${ }^{1}$
}

Received: 5 July 2015/Accepted: 8 July 2015/Published online: 21 July 2015

(C) Springer International Publishing AG 2015

\begin{abstract}
Procedures to perform structural design of pavements are detailed in various design guidelines. Even though the recommendations may be different across the different guidelines, some of the underlying principles are similar. The present paper briefly reviews various pavement design guidelines on structural design of asphalt pavements with reference to the design principles employed. The focus is primarily kept on the mechanistic-empirical pavement design approach. The discussion covers few specific aspects of asphalt pavement design, and does not intend to present an exhaustive treatise on the subject.
\end{abstract}

Keywords Pavement design $\cdot$ Asphalt pavement $\cdot$ Design guidelines

\section{Introduction}

An asphalt pavement is made up of multiple layers, namely subgrade, sub-base, base, surfacing and wearing course. While there are design considerations involved in a pavement from the geometric, functional and drainage aspects, the structural design indicates estimation of appropriate thicknesses of the pavement layers.

Different kinds of materials are used to construct individual layers of a pavement structure. These materials show complex response when subjected to load, temperature and moisture variations. The engineering properties of a pavement material depends on the relative composition of

Animesh Das

adas@iitk.ac.in

1 Department of Civil Engineering, Indian Institute of Technology Kanpur, Kanpur, Uttar Pradesh 208016, India its constituents. The composition of a pavement material is finalized through appropriate mix design, so that the desirable levels of various engineering properties of the material are achieved. However, sometimes a pair of desirable properties may show conflicting trends with the variation of a constituent of the mix. For example, with the increase of the asphalt binder content in the asphalt mix, the fatigue performance may improve, but the stiffness modulus value may start decreasing. From pavement design stand-point, both (i) good fatigue performance, as well as (ii) high stiffness modulus of the asphalt mix, are desirable. Thus, appropriate (i) choice of pavement material for the individual pavement layers, (ii) mix design for each of these materials and (iii) estimation of engineering properties (which are used as design input), are integral parts of the process of pavement design [1-16].

Environmental parameters used in pavement design primarily include variation of temperature and moisture conditions (including freezing and thawing situations) during the service period of the pavement. In the design guidelines such variations are accounted either (i) considering expected/equilibrium value of the temperature and the moisture content during the design period $[4,8,10,16]$ or, (ii) by dividing the total design period into certain time intervals and considering the effects of temperature and moisture content (in terms of incremental damage) for these time intervals $[1,15]$. For design purpose, it is generally assumed that the temperature affects the stiffness of the asphalt layer and the moisture content affects the stiffness of the unbound granular layer and the subgrade. Further, it may be noted that there always exists a temperature profile and moisture content profile (that is, variation along the depth of the pavement). For design purpose, a representative values of temperature and moisture content are chosen which carry the equivalent effects of such variations along the depth $[17,18]$. 
Traffic parameters involve considerations of traffic volume, axle load spectrum, tyre contact pressure, wheel and axle configuration, lateral wander of wheel path, traffic growth rate etc. Guidelines suggest various empirical factors or, computational approaches to take into account of these parameters so as to convert the estimated cumulative traffic volume (within the design period) to equivalent number of standard axle load repetitions [2-5, 8-10, 12, $16,19,20]$. Sometimes, the damage caused by individual axle load groups are estimated separately.

The next section discusses the basic principles of asphalt pavement design and how different guidelines employ these principles to evolve respective design recommendations.

\section{Principles of Asphalt Pavement Design}

Different methods of pavement design are proposed at different points of time, for example, CBR-thickness approach, limiting deflection approach, bearing capacity approach, equivalent granular thickness approach and so on [13, 14, 21-23].

In AASHTO 1993 method [19], the pavement is designed based on an index which represents the overall strength of the pavement structure. This index is a function of the composition of individual layers and their thicknesses [19]. Some pavement design guidelines recommend use of AASHTO 1993 [19] method in conjunction with other local recommendations [2, 5, 24, 25]. In some guidelines, pavement deign recommendations are provided in template/tabular forms. These templates are either based on prior experience on the performance of pavements or prior design calculations [6, 10, 26-29].

The principles of mechanistic-empirical pavement design approach (initially known as analytical pavement design) evolved during 1960s [14, 21, 30, 31]. A number of guidelines at present follow mechanistic-empirical approach for design of asphalt pavements [1, 3, 4, 7, 8, 12, 14, 16, 20, 32-35].

Figure 1 presents a simplified thought process involved in the design of asphalt pavement using mechanistic-empirical method. Elaborate flow-charts are available in the literature $[13,14,22,36]$ and in various guidelines $[1,4,6$, $15,16,20,37,38]$. In this approach, trial thicknesses of the pavement layers are assumed and the critical stress/strain values (typically strain is considered for design of asphalt pavements) at the critical locations are computed by structural analysis of the pavement. The computed strain values are compared with the allowable values and the design thicknesses are finalized through iterations. This process is repeated for all the types of structural distresses which are dependent on the layer thicknesses.

The concept of estimation of allowable strain is further illustrated in Fig. 2. The upper part of Fig. 2 schematically

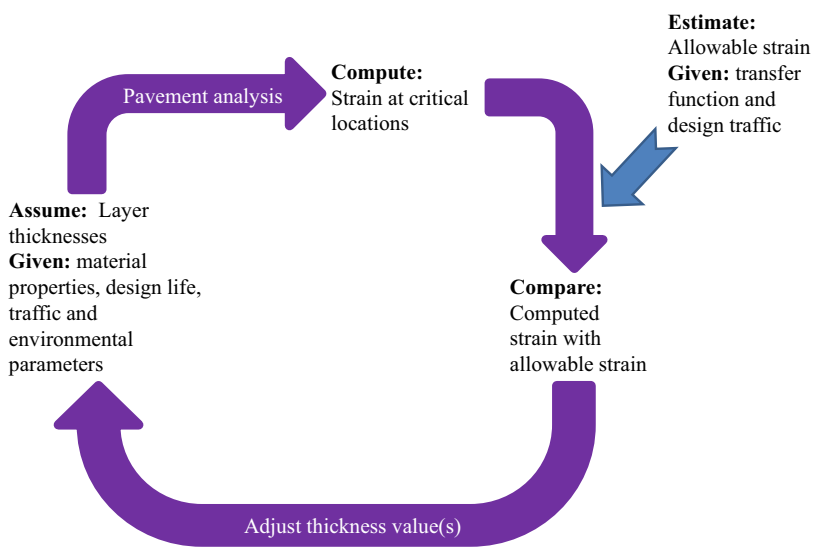

Fig. 1 A simplified thought-process involved in structural design of asphalt pavement using mechanistic-empirical approach

shows that the structural distress increases (possibly with increasing rate as shown in the diagram) with the increase of number of repetitions (the repetitions can be traffic load repetitions or environmental cycles). For different pavement structures (that is, pavements with different thicknesses, shown as 1, 2 and 3 in Fig. 2), a same level of distress would occur at different number of repetitions. That is, considering distress level ' $\mathrm{p}$ ' as the failure distress level (for a given type of structural distress being considered in the design) the pavement structure 3 would have more longevity than the pavement structure 2 , and the pavement structure 2 would have more longevity than the pavement structure 1. The lower part of Fig. 2 shows that for a given initial critical strain (when the pavement is built for the first time and the first load is applied), the pavement can sustain a given number of repetitions till failure, when distress level ' $p$ ' is defined as structural failure. For a

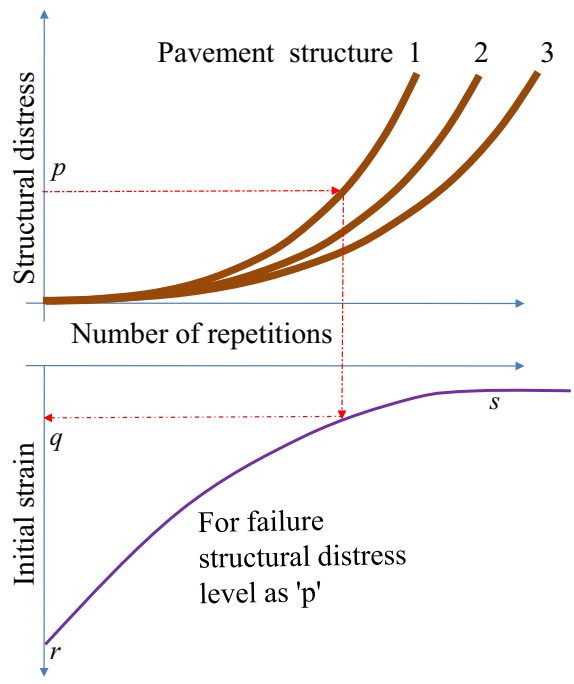

Fig. 2 The concept involved in estimation of allowable strain 
pavement design problem, this initial strain is treated as the allowable strain.

Thus, from Fig. 2, the pavement structure 1 should be designed for an allowable strain of ' $q$ ' if a distress level of ' $p$ ' is defined as the structural failure level of a specific type of distress considered in the design. It is interesting to note that, in pavement design problems, the allowable strain (generally) is a function of number of load repetitions, for the various types of structural distresses considered in the design process [39]. Such consideration makes the pavement design approach unique, in contrast to the design approaches generally followed for design of other civil engineering structures.

Consideration of repetitions in the design process necessitates studies on how the damage propagates with the load repetitions. However, understanding the mechanism of damage propagation is a complex task. Empirical equations are, therefore, used to establish a link between the allowable strain and the number of load repetitions. Generally, tests conducted in the laboratory are calibrated [40, 41] from field performance of in-service roads to develop these empirical equations. These are also known as transfer functions (refer Fig. 1). Various such transfer functions are proposed by the past researchers [9, 13, 15, 17, 36, 42-48] and are used in the design guidelines $[1,3,4,7,8,16,33$, 49]. Obviously, these empirical equations are valid for the local material, environmental and traffic conditions for which these are calibrated. Hence, the current asphalt pavement design approach is a mechanistic-empirical method, and not yet fully mechanistic.

Referring to Fig. 2 again, it can be said that if the strain level is 's' (or lower), the pavement will be able to theoretically sustain infinite number of load repetitions. This is known as endurance limit and is discussed in the next section in connection with the design of perpetual pavement. The other extreme point on the diagram is shown as ' $r$ '. It is that strain level at which the structure can sustain only a single application of load (it may be noted that the graph represented in the lower part of Fig. 2 is typically plotted on log-log scale so that the transfer function appears linear). For concrete pavement (where bending stress is used instead of strain) this value indicates the modulus of rupture.

Although the principle is the same (as explained in Fig. 2), some guidelines [1, 15] do not specify allowable strain. In this case, first a trial pavement section is chosen and the expected distress level is estimated at the end of the design period. If the distress level is within the permissible limit, the design is accepted, else the thicknesses are modified in the next iteration [15, 50].

The guidelines for design of asphalt pavement using mechanistic-empirical method generally recommend use of associated software(s) [1, 3, 4, 7, 8, 14, 16, 20]. These softwares [13, 14, 21] are used for structural analysis of asphalt pavement to compute the critical strain values. The design module of the software, if present, iteratatively finalizes the design thicknesses (refer to Fig. 1). Further considerations involved in finalization of thicknesses for design of (i) new asphalt pavement and (ii) asphalt overlay over the existing pavement are discussed in the following.

\section{Design of a New Asphalt Pavement}

Figure 3 shows a conceptual diagram of a pavement design chart considering fatigue (bottom up) and rutting distresses. A three-layer asphalt pavement structure is assumed in this case, constituted with an asphalt layer, an unbound granular layer and a subgrade. Two design variables (that is, asphalt and granular layer thicknesses) and two structural distresses (that is, fatigue and rutting) are considered.

Figure 3 shows that various combinations of layer thicknesses are possible for which the design is safe (for the design traffic considered). For example, if the point ' $\mathrm{O}$ ' is chosen for design traffic $D T_{1}$, the corresponding asphalt layer thickness will be OQ and granular layer thickness will be EQ. It may also be noted that for this design solution the pavement is expected to simultaneously fail in fatigue and rutting at the expiry of design life of $D T_{1}$ traffic repetitions. Various design charts (based on mechanisticempirical principle) developed by different organizations (although all the guidelines may not necessarily provide ready-made design charts) are variants of what is shown in Fig. 3. The choice of axes makes the diagram look different. For example, in Shell [16] and Austroads [4] design charts, axes similar to what is shown in Fig. 3 are chosen. In Asphalt Institute method [3] traffic is taken as X-axis

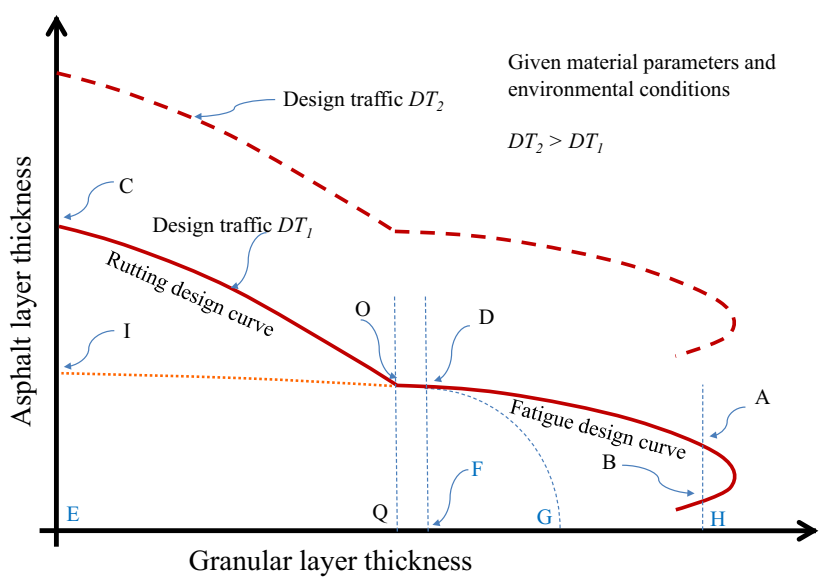

Fig. 3 A schematic diagram of asphalt pavement design chart considering fatigue and rutting 
and subgrade modulus is taken as Y-axis. In Indian Roads Congress [8] traffic is taken as $\mathrm{X}$-axis and both the thicknesses are presented along $\mathrm{Y}$-axis.

As shown in Fig. 3, if the design traffic increases (say, from $D T_{1}$ to $D T_{2}$ ), both the fatigue and rutting design curves are expected to move upwards. This is because higher traffic will require larger design thickness. Again, the rutting design curve will shift in the upward direction if, for instance, (i) the design temperature increases or, (ii) the design stiffness modulus of asphalt decreases. However, shift of the fatigue design curve cannot be ascertained easily in these two cases, because of the possible reciprocal relationship that exists between the fatigue performance and the stiffness modulus of asphalt mix.

Figure 3 shows that the rutting design curve meets the $\mathrm{Y}$-axis at ' $\mathrm{C}$ '. That is, the granular layer thickness is zero at this design point. Such a pavement may be called as full depth asphalt pavement $[3,4,16,18,51]$. Figure 4 shows a schematic diagram of a full depth asphalt pavement design chart. In Fig. 4 it is observed that the design thickness of asphalt layer increases as the expected traffic repetitions increase. Since thickness requirement from rutting consideration is generally higher than that of from the fatigue consideration (for example, comparing between point ' $\mathrm{C}$ ' and point ' $\mathrm{I}$ ' in Fig. 3), the rutting consideration should have always governed the pavement design. However, with appropriate mix design it should be possible to develop a mix with stronger rut resistance [52]. This is another example of interplay (as mentioned in the "Introduction" section of this paper) between the mix design and structural design [11, 13]; hence the rutting design curve takes a shape as shown in Fig. 4. The full depth pavement design charts recommended in the guidelines [3, 4, 16], may sometimes appear to be different than the way it is shown in Fig. 4. This is due to choice of axes, as discussed for the case of Fig. 3 earlier.

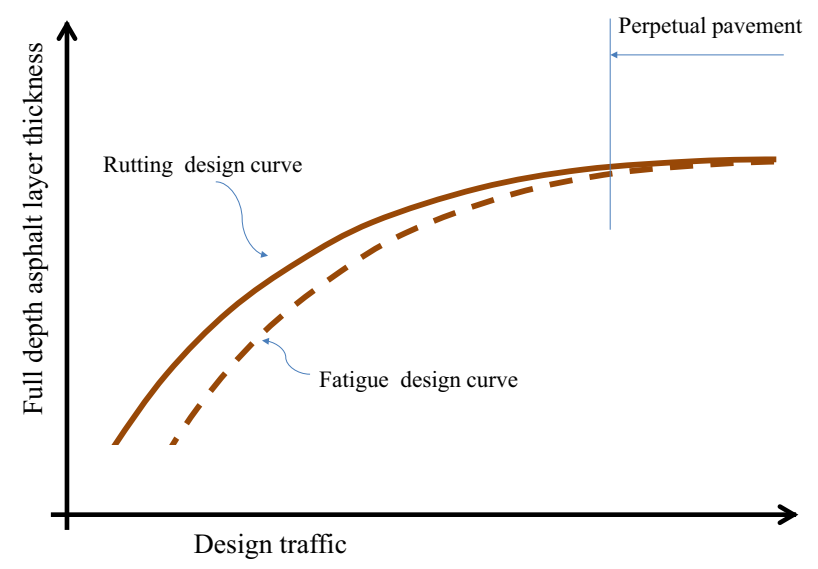

Fig. 4 A schematic diagram of full-depth asphalt pavement design chart
From Fig. 4 it can be seen that beyond certain thickness, the longevity of the pavement structure becomes theoretically infinite. This is known as perpetual pavement [53, 54]. In perpetual pavement, a relatively thick asphalt layer thickness is provided (than the conventional pavements designed for finite design life), so that critical strain becomes comparable to the endurance limit [55-58].

The paragraph above has discussed one of the extreme ends of the design curve (refer to Fig. 3); an interesting observation can be made on the other extreme end of the design curve. It is seen that when the granular layer thickness is quite high, the design curve turns in the reverse direction. That is, referring to Fig. 3, for a given granular thickness EH, two design asphalt layer thicknesses are possible, these are HB and HA (a pavement designer will obviously choose the lower thickness). This happens because, at a higher thickness of granular layer, when the thickness of asphalt layer is lowered further during the process of design iterations, the strain (horizontal tensile) at the bottom of the asphalt layer (below some threshold value of the thickness) starts decreasing; further reduction in asphalt layer thickness even reverses the strain from tensile to compressive $[4,38]$. Thus, in principle, it is also possible to design a thin asphalt layer over a thick granular layer [20], but sometimes there may be issues especially for heavy-trafficked urban roads [4].

Instead of conventional hot-mix asphalt with unbound granular base/sub-base layer, it is possible to utilize other pavement materials for example, recycled asphalt layer [59], asphalt layer with emulsified binder [60] or, modified binder, cementicious layer with marginal aggregates as base/sub-base [9, 48], industrial and domestic waste materials as alternative materials [61, 62] and so on.

For incorporation of various new materials in the design, these materials need to be characterized in terms of their environmental impact, material properties (physical, chemical and engineering), economy, expected performance and so on. Various guidelines provide stipulations on usage of such materials in pavement design [1-5, 7, 8, 12, 15, 16, 20, 25, 34, 49, 63].

When it is decided to use a new material in pavement design, the design needs to be re-worked [62]. For example, when a cementicious material is decided to be used as a base layer, it may provide benefits in terms of (i) possible utilization of locally available marginal aggregates and (ii) possible reduction of the asphalt layer design thickness, because of the reduction of the strain value due to higher stiffness of cementicious layer and its contribution to additional fatigue life [4, 48, 49]. However, additional cost due to the usage of cemented material, shrinkage potential and long term durability of the cementicious material, special construction requirements etc. need to be considered while finalizing the design [4, 48, 49]. 


\section{Design of Overlay and Subsequent Overlays}

A pavement gradually deteriorates due to its exposure to environment and traffic. Overlaying is one of the maintenance measures, where additional asphalt layer thickness is provided to the existing pavement. Limiting deflection [9, 64-66], equivalent thickness [19, 64, 65], and mechanisticempirical method $[15,63]$ are the different approaches for design of overlay thickness.

The mechanistic-empirical overlay design principle can be explained in the following manner. Consider any design point (say 'D') on the pavement design curve presented in Fig. 3. The corresponding asphalt and granular layer thicknesses are, therefore, DF and EF respectively. After serving the design period of $D T_{1}$ (say), the asphalt layer deteriorates resulting in reduction of stiffness. In a conservative sense, one may consider that the stiffness of the deteriorated asphalt layer is equivalent to that of the granular layer. In that case, the asphalt overlay can be designed considering the total existing granular layer thickness as EG (as shown schematically in Fig. 3) and the same design chart can be utilized. However, due to possibilities of reflection cracking, the transfer functions for overlay design may be different than those of used for design of pavement for the first time.

Further, the stiffness modulus value of the deteriorated asphalt layer may not be as low as a granular layer. Thus, for estimation of the in situ stiffness values (for all the individual layers) at any given point of time, suitable nondestructive testing method, for example, falling weight deflectometer (FWD) can be adopted [15, 19, 67, 68].

Planned staged construction of asphalt layer is a situation when the asphalt layer is constructed in stages [3, 4]. The possible reasons for adopting planned staged construction can be identified as (i) budgetary restrictions, (ii) uncertainty in the traffic prediction, (iii) unfavourable weather condition for continuing construction etc. [4]. If the time gap between construction of two consecutive asphalt layers is small, (i) deterioration of the asphalt layer (provided in the first stage) can be assumed to be negligible, or, (ii) some deterioration can be assumed corresponding to the time already passed, and the thickness for the asphalt layer for the second stage can be estimated (following the principle illustrated in Fig. 1) [3, 4].

A pavement design problem (for new pavement as well as overlay), for a given set of input parameters, is expected to have multiple design solutions. Economic analysis is generally used to choose the best design $[2,4,15,19,20$, 69]. Further, a pavement in its entire service period may undergo many rounds of rehabilitation and maintenance activities. Planning (at the initial design stage) for appropriate maintenance measures and their application timings for a given road stretch (or for a road network) is an interesting but complex problem [70].

\section{Closure}

A vast literature is available on asphalt pavement design. Each region, or country or, state or, even a county may be following a particular pavement design guidelines, somewhat different than the rest others. The input parameters, the design equations, and the design recommendations provided in these guidelines may vary widely. Hence, the final design thickness values, across different guidelines (for the same set of design input), may even be found to be different [16, 37, 71-73]. The present brief paper highlights that the basic principles of mechanistic-empirical pavement design adopted across various guidelines, are, however, similar.

Pavement design involves consideration of repetitions of load (traffic repetitions and environmental cycles). Thus, it is important to be able to predict the propagation of damage of an in-service pavement with the progression of repetitions [74-76]. But, given the complexities with the material behaviour, structure and the loading pattern, developing a comprehensive theoretical model is still a complex task. Thus, for design purpose, equations empirically relating the initial strain (or stress) values (generally due to static loading) to the number of repetitions till failure observed in the field, are used. The form of these equations across different guidelines may be different, and even if the form is similar, the calibration constants may vary widely $[9,15,17,20,36,42-48]$.

Further, Miner's postulation [77] is generally used for estimation of cumulative damage in the pavement due to load repetitions $[1,3,7,9,15,18,20,33,36,37,58]$. This assumes damage caused by different loads applied at different points of time are linearly additive. Considering the complex response of the pavement materials (which are dependent on time, stress level, and considering the healing phenomenon observed in asphalt mix) there is possibly a need to explore other models for calculation of cumulative damage [50,78].

The mechanistic-empirical pavement design approach followed in various pavement design guidelines still has significant portion of empirical content. It is envisaged that rigorous theoretical research in conjunction with laboratory and field observations would eventually lead to a more mechanistic approach of pavement design. 
Disclaimer A number of old and new pavement design guidelines have been referred in this paper to discuss various principles related to asphalt pavement design. The pavement design guidelines referred in this article are only representative, and in no way provides an exhaustive account of the different pavement design practices followed across the world.

\section{References}

1. American Association of State Highway and Transportation Officials (2008) AASHTO mechanistic-empirical pavement design guide: a manual of practice, interim edition. American Association of State Highway and Transportation Officials, Washington, DC

2. Alberta Transportation and Utilities (1997) Pavement design manual. http://www.transportation.alberta.ca/Content/docType233/ Production/pavedm2.pdf. Accessed 3 July 2015

3. Institute Asphalt (1999) Thickness design—asphalt pavements for highways and streets, vol 1, 9th edn., Manual series Asphalt Institute, Lexington

4. Austroads Ltd. (2012) Guide to pavement technology part 2: pavement structural design AGPT02-12. Austroads Ltd., Sydney

5. Colorado Asphalt Pavement Association (2006) Guideline for the design and use of asphalt pavements for Colorado roadways, 2nd edn. Colorado Asphalt Pavement Association. http://co-asphalt. com/wp-content/uploads/2015/03/Design_guide_for_Roadways-. pdf. Accessed 20 June 2015

6. European Commission, Directorate of General Transport (1999) Development of new bituminous pavement design method COST 333. Final report of the action. European Commission, Directorate of General Transport, Brussels

7. Federal Aviation Agency (2009) Airport pavement design and evaluation. Advisory circular, 150/5320-6E. http://www.faa.gov/ documentLibrary/media/Advisory_Circular/150_5320_6e.pdf. Accessed 21 June 2015

8. Indian Roads Congress (2012) Guidelines for the design of flexible pavements IRC:37-2012, 3rd revision. Indian Roads Congress, New Delhi

9. Jameson G (2013) Technical basis of Austroads guide to pavement technology part 2: pavement structural design. Research report ARR 384, ARRB Group Ltd.

10. Overseas Center Transport Research Laboratory (1993) A guide to the structural design of bitumen-surfaced roads in tropical and sub-tropical countries. Overseas road note 31. Overseas Center Transport Research Laboratory, Crowthorne

11. May R, Witczak MW (1992) Integrating flexible pavement mix and structural design. In: Proceedings of the 7th international conference on the structural design of asphalt pavements, University of Nottingham, vol I, pp 141-156

12. Michigan Department of Transportation (2015) Michigan DOT user guide for mechanistic-empirical pavement design. Michigan Department of Transportation, Traverse. https://www.michigan. gov/documents/mdot/MDOT_Mechanistic_Empirical_Pavement_ Design_User_Guide_483676_7.pdf. Accessed 22 June $201 \overline{5}$ (interim edition)

13. Monismith CL (1992) Analytically based asphalt pavement design and rehabilitation: theory to practice, 1962-1992. Transp Res Rec 1354:25-26

14. Monismith CL (2004) Evolution of long-lasting pavement design methodology: a perspective, distinguished lecture. In: International symposium on design and construction of long lasting asphalt pavements, Auburn University. http://asphalt.org/down loads/Monismith_lecture.pdf. Accessed 22 June 2015
15. NCHRP (2004) Mechanistic-empirical design of new and rehabilitated pavement structures. NCHRP design guide. National Cooperative Highway Research Program (NCHRP), Project 1-37A, Washington, DC. http://www.trb.org/mepdg/guide.htm. Accessed 16 Apr 2015

16. Shell International Petroleum Company Limited (1978) Shell pavement design manual-asphalt pavement and overlays for road traffic. Shell International Petroleum Company Limited, London

17. Claessen AIM, Edwards JM, Sommer P, Uge P (1977) Asphalt pavement design - the Shell method. Proceedings of 4th international conference on the structural design of asphalt pavements, vol 1. University of Michigan, Ann Arbor, pp 39-74

18. Witczak MW (1972) Design of full-depth asphalt airfield pavement.In: Proceedings of 3rd international conference on the structural design of asphalt pavements, vol I, London, pp 550-567

19. American Association of State Highway and Transportation Officials (1993) AASHTO guide for design of pavement structures. American Association of State Highway and Transportation Officials, Washington, DC

20. South African National Roads Agency Ltd. (2014) Pavement design, chapter 10. In: South African pavement engineering manual. South African National Roads Agency Ltd. http://www. nra.co.za/content/SAPEM-Chapter-10-2nd-edition-2014.pdf?Ses sion_ID=fe8eab1e07c232f7ade250ad73fc1392. Accessed 24 June 2015

21. Brown SF (1997) Achievements and challenges in asphalt pavement engineering. In: Proceedings of the 8th international conference on asphalt pavements, Seattle, pp 1-23. http://asphalt. org/downloads/Browns_lecture.pdf. Accessed 13 June 2015

22. Huang YH (2004) Pavement analysis and design, 2nd edn. Pearson Prentice Hall, Englewood Cliffs

23. Porter OJ (1942) Foundations for flexible pavements. In: Proceedings of Highway Research Board, Washington, DC, vol 22, pp 100-143

24. Department of Transportation, State of Delaware (2014) Road design manual. Department of Transportation, State of Delaware. http://www.deldot.gov/information/pubs_forms/manuals/road_ design/index.shtml. Accessed 16 June 2015

25. Florida Department of Transportation (2012) Flexible pavement design manual. Florida Department of Transportation, Gainesville. http://www.dot.state.fl.us/rddesign/PM/pcs/FlexiblePave mentManual.pdf. Accessed June 13, 2015

26. Asphalt Paving Association of Iowa (2008) Asphalt pavement design guide. Asphalt Paving Association of Iowa, Ames. http:// www.apai.net/cmdocs/apai/designguide/AsphaltComposi teSmFst.pdf. Accessed 13 June 2015

27. RstO 2000 (1999) Richtlinien für die Standardisierung des Oberbaues von Verkehrsflächen, Entwurf (in German)

28. Japan Road Association (1989) Manual for asphalt pavement. Japan Road Association, Tokyo

29. Transport and Road Research Laboratory (1970) A guide to the structural design for new roads. Road note 29 , RN 29, 3rd edn. HMSO, London

30. Dorman GM (1962) The extension to practice of a fundamental procedure for design of flexible pavements. In: Proceedings of the 1 st international conference on the structural design of asphalt pavements, Ann Arbor, Michigan, pp 785-793

31. Monismith CL, Secor KE, Blackmer W (1961) Asphalt mixture behaviour in repeated flexure. Proc Assoc Asph Paving Technol 30:188-222

32. Colorado Department of Transportation (2015) M-E pavement design manual. Colorado Department of Transportation, Durango. https://www.codot.gov/business/designsupport/materials- 
and-geotechnical/manuals/pdm/2015-pdm/view. Accessed 21 June 2015

33. Union des Syndicats de l'Industrie Routière Française (1997) French design manual for pavement structures. Guide Technique, LCPC and SETRA. Union des Syndicats de l'Industrie Routière FrançaiseM, Paris

34. Indiana Department of Transportation (2013) Indiana design manual 2013, part 3, roadway. Indiana Department of Transportation, http://www.in.gov/indot/design_manual/design_man ual_2013.htm. Accessed 21 June 2015

35. Pierce LM, McGovern G (2014) Implementation of the AASHTO mechanistic-empirical pavement design guide and software, NCHRP synthesis 457. TRB, Washington, DC

36. Brunton JM, Brown SF, Pell PS (1987) Developments to the Nottingham analytical design method for asphalt pavements. In: Proceedings of 6th international conference on the structural design of asphalt pavements, University of Michigan, Ann Arbor, vol I, pp 366-377

37. Ingason $\mathrm{T}$, Scarpas $\mathrm{A}, \mathrm{M}$ de Lurdes Antunes, de Almeida JR, Lipoglavšek B, Jamnik J, Moreno AM, Perret J (2000) Advanced models for analytical design of European pavement structures: RO-97-SC.2137. Progress report of COST333 and AMADEUS projects. Centre de Recherches Routières, Europäische Kommission, Charleroi. http://www.transport-research.info/Upload/ Documents/200310/amadeus.pdf. Accessed 6 June 2015

38. AUSTROADS (2004) Pavement design - a guide to the structural design of road pavements. AUSTROADS, Sydney

39. Das A (2009) A reliable design of asphalt pavement from structural considerations. Editor's corner. Int J Pavement Res Technol 2(1):4

40. Al-Qadi IL, Nassar WN (2003) Fatigue shift factors to predict HMA performance. Int J Pavement Eng 4(2):69-76

41. Tseng KH, Lytton RL (1990) Fatigue damage properties of asphaltic pavements. Transp Res Rec 1286:150-163

42. Brown SF, Pell PS (1972) A fundamental structural design procedure for flexible pavements. In: Proceedings of 3rd international conference on asphalt pavements, vol I, 1972, pp 369-381

43. Corté JF, Goux MT (1996) Design of pavement structures: the French technical guide. Transp Res Rec 1539:116-124

44. Das A, Pandey BB (1999) Mechanistic-empirical design of bituminous roads : an Indian perspective. J Transp Eng 125(5):463-471

45. Delgadillo R, Wahr C, Alarcón J (2011) Toward implementation of the mechanistic-empirical pavement design guide in Latin America preliminary work in Chile. Transp Res Rec 2226:142-148

46. Medina J, Pressler ES, Pinto S, Motta L (1982) The study of resiliency for pavement design in Brazil. In: Proceedings of 5th international conference on the structural design of asphalt pavements, Delft University of Technology, pp 726-732

47. Shook JF, Finn FN, Witczak MW, Monismith CL (1982) Thickness design of asphalt pavements-the Asphalt Institute method. In: Proceedings of the 5th international conference on the structural design of asphalt pavements, Delft University of Technology, The Netherlands, vol I, pp 17-44

48. Theyse HL, Beer M, Rust FC (1996) Overview of the South African mechanistic pavement design analysis method. Transp Res Rec 1539:6-17

49. Committee of Land Transport Officials (1996) Structural design of flexible pavements for interurban and rural roads: draft TRH4. TRANSPORTEK, CSIR, Pretoria

50. National Cooperative Highway Research Program (2006) Independent review of the mechanistic-empirical pavement design guide and software, RRD 307. National Cooperative Highway Research Program. http://onlinepubs.trb.org/onlinepubs/nchrp/ nchrp_rrd_307.pdf. Accessed 19 Apr, 2015
51. Thompson MR (1987) ILLI-PAVE based full depth asphalt concrete pavement. In: Proceedings of 6th international conference on the structural design of asphalt pavements, Ann Arbor, Michigan, vol I, pp 13-22

52. Brown R, Coole L (1999) Designing stone matrix asphalt mixtures for rut-resistant pavements. NCHRP report 425. TRB, Washington, DC

53. Thompson MR, Carpenter SH (2004) Design principles for long lasting HMA pavements. In: Proceedings of international symposium on design and construction of long lasting asphalt pavements, NCAT, Auburn, pp 365-384

54. Von Quintus HL (2001) Hot mix asphalt layer thickness design for longer life bituminous pavements. Transportation research circular, number 503. TRB, Washington, DC, pp 66-78

55. Martin JS, Harvey JT, Long F, Lee E, Monismith CL, Herritt K (2001) Long-life rehabilitation design and construction, I-710 Freeway, Long Beach, California. Transportation Research Board circular no. 503. TRB, Washington, DC, pp 50-65

56. Nunn M, Brown A, Weston D, Nicholls JC (1997) Design of long-life flexible pavements for heavy traffic, report no. 250. Transportation Research Laboratory, Berkshire

57. Sidess A, Uzan J (2009) A design method of perpetual flexible pavement in Israel. Int J Pavement Eng 10(4):241-249

58. Timm DH, Newcomb DE (2006) Perpetual pavement design for flexible pavements in the U.S. Int $\mathrm{J}$ Pavement Eng 7(2):111-119

59. Aravind K, Das A (2007) Pavement design with central plant hotmix recycled asphalt mixes. Constr Build Mater 21(5):928-936

60. Santuccci LE (1977) Thickness design procedure for asphalt and emulsified asphalt mixes. In: Proceedings of 4th international conference on the structural design of asphalt pavements, Ann Arbor, Michigan, vol I, pp 424-456

61. Stroup-Gardiner M, Wattenberg-Komas T (2013) Recycled materials and byproducts in highway applications. A synthesis of highway practice, vol 1-8., NCHRP synthesis 435Transportation Research Board, Washington, DC

62. Van Dam TJ, Harvey JT, Muench ST, Smith KD, Snyder MB, AlQadi IL, Ozer H, Meijer J, Ram PV, Roesler JR, Kendall A (2015) Towards sustainable pavement systems: a reference document, FHWA-HIF-15-002. Federal Highway Administration, Washington, DC

63. California Department of Transportation (2012) Highway design manual. California Department of Transportation, Sacramento. http://www.dot.ca.gov/hq/oppd/hdm/pdf/english/HDM_Complete_ 07Mar2014.pdf. Accessed 20 June 2015

64. Institute Asphalt (1983) Asphalt overlays for highway and street rehabilitation, vol 17., Manual seriesAsphalt Institute, Lexington

65. Crovetti J (2005) Development of rational overlay design procedures for flexible pavements. Final report, report \#0092-00-05. Department of Civil and Environmental Engineering, Marquette University, Wisconsin Department of Transportation

66. Indian Roads Congress (1997) Guidelines for strengthening of flexible pavements using Benkelman beam deflection technique, IRC:81-1997. Indian Roads Congress, New Delhi

67. European Commission, Directorate of General Transport (2005) Use of falling weight deflectometers in pavement evaluation COST 336, final report. European Commission, Directorate of General Transport

68. Indian Roads Congress (2014) Guidelines for structural evaluation and strengthening of flexible pavements using falling weight deflectometer (FWD) technique, IRC:115 2014. Indian Roads Congress, New Delhi

69. State of California, Department of Transportation (2013) Life cycle cost analysis procedures manual. State of California, Department of Transportation, Sacramento. http://www.dot.ca. gov/hq/maint/Pavement/Offices/Pavement_Engineering/LCCA_ 
Docs/LCCA_25CA_Manual_Final_Aug_1_2013_v2.pdf. Accessed 3 July 2015

70. Irfan M, Khurshid MB, Bai Q, Labi S, Morin TL (2012) Establishing optimal project-level strategies for pavement maintenance and rehabilitation - a framework and case study. Eng Optim 44(5):565-589

71. Caliendo C (2012) Local calibration and implementation of the mechanistic-empirical pavement design guide for flexible pavement design. J Transp Eng 138(3):348-360

72. Carvalho RL, Schwartz CW (2006) Comparison of flexible pavement designs: AASHTO empirical versus NCHRP 1-37A mechanistic-empirical. Transp Res Rec 1947:167-174

73. Perraton D, Baaj H, Carter A (2010) Comparison of some pavement design methods from a fatigue point of view. Road Mater Pavement Des 11(4):833-861
74. Collop A, Cebon D (1996) Stiffness reduction of flexible pavements due to cumulative fatigue damage. J Transp Eng 122(2):131-139

75. Oliveira JRM, Thom NH, Zoorob SE (2008) Design of pavements incorporating grouted macadams. J Transp Eng 134(1):7-14

76. Jameson GW, Sharp KG, Vertessy NJ (1992) Full-depth asphalt pavement fatigue under accelerated loading. In: Proceedings of the 7th international conference on asphalt pavements, vol 2, Nottingham, pp 180-200

77. Miner MA (1945) Cumulative damage in fatigue. Trans ASME 67:A159-A164

78. Fatemi A, Yang L (1998) Cumulative fatigue damage and life prediction theories: a survey of the state of the art for homogenous materials. Int J Fatigue 20(1):9-34 